\section{Ano Internacional da Química}

Ao iniciar o estudo da Química junto a um grupo novo de estudantes universitário costumo chamar a atenção para a peculiaridade da preocupação da ciência Química: olhar e compreender o mundo material e sua transformação sob um ponto de vista novo, muito além do que conseguem alcançar os nossos olhos e só possível através de um sistema conceitual muito especial e que constitui o conhecimento químico. Estudar Química é significar esse mundo novo criado que permite, ao mesmo tempo, o entendimento do real dado, sua transformação e a criação de um novo real que enriquece o anterior, preserva-o e também pode degradá-lo. Aprender Química é tomar consciência das condições ambientais muito especiais que permitiram a organização atômico-molecular de modo tal que proporcionou o fenômeno mais espetacular que se pode imaginar no Cosmos, que é a vida na Terra.

Sob o ponto de vista da Química, uma centena de moléculas, não muito mais do que isso, todas de organização bastante simples, como vinte aminoácidos, cinco bases, cinco açúcares, alguns lipídeos e mais fosfato e outras poucas moléculas dão origem ao fenômeno vida e à nossa própria capacidade de pensar sobre ela. Sob o ponto de vista da Química, a organização dessas moléculas e, principalmente, a "cooperação" entre elas para produzir o fenômeno da vida, que foi precedido do fenômeno da autorreplicação, é extraordinário. Sabem-no os químicos que as condições de formação de uma nova molécula são muito especiais, tornando-se um desafio entender e enfrentar tal complexidade de condições e fatores que permitiram a vida.Assim, muito diferente do que circula no senso comum sobre a presença da Química no meio tecnossocial - uma Ciência que degrada o meio, prejudica a saúde, destrói a vida -, o conhecimento químico verdadeiro firma cada dia seu compromisso para uma vida melhor na
Terra. Esta consciência precisa ser constituída no contexto educacional básico em todas as escolas e universidades. É preocupação dos educadores químicos que isso possa acontecer, não com a finalidade de mudar o senso comum, mas proporcionar uma educação de melhor qualidade em todos os sentidos e para todos.

Sabemos que é de longínqua data a habilidade construída e culturalmente transmitida de os seres humanos lidarem com diversos materiais e sistemas, que ainda são do domínio da Química, como o domínio do fogo e a adequação de tintas naturais para fins de registros escritos. Porém, o fato químico, mesmo no contexto das ciências naturais e exatas, é bastante recente na história da humanidade. Isso compreende a ideia de um pequeno número de elementos constituintes do mundo material e sua (re)organização para a criação de novos materiais e novas substâncias. Podemos nos perguntar por que este é um fenômeno tão recente, com pouco mais de 200 anos! Com base em Vigotski, aliamo-nos à ideia de que, mais que a ambição humana ou o desejo da eternidade, é a necessidade que move os humanos, a partir disso criam o mundo cultural, no qual os artefatos tecnológicos ocupam papel central.A necessidade de um conhecimento que pudesse produzir substâncias novas, substituindo aquelas que a natureza não produzia com a agilidade e eficiência requerida no ritmo da Revolução Industrial, tornou-se crucial e com ela a crescente demanda de conhecimento que denominamos Química. O caso mais ilustrativo dessa época é o desenvolvimento da indústria química de base, associada ao tingimento de tecidos e à síntese de diversas tintas artificiais. Sem sermos ingênuos, temos de saber que os artefatos, só possíveis mediante aplicação de novos conhecimentos científicos, também são mercadorias e como tais permitem a posse e a 
conversão em lucro, mais que isso, a produção de necessidades de consumo desenfreado, fruto da propaganda!

As construções teóricas sobre a estrutura da matéria, na forma de teorias moleculares e de produção das condições controladas e aceleradas entre as microestruturas proporcionam ao homem contemporâneo a competência de criar qualquer tipo de substância e/ou material cujas características possa imaginar e descrever. Isso dá ao ser humano, ao mesmo tempo, muito poder na transformação da natureza, também muita responsabilidade.

Interagir nesse mundo novo, com possibilidade de opção de seguir por um caminho ou outro, de consumir determinado artefato ou outro, exige entendimento e discernimento de cada pessoa. Os artefatos da química ou os produtos químicos fazem parte do meio tecnossocial, mas o conhecimento químico, a consciência das possibilidades de transformação e a permanência dos elementos em determinado meio, a ideia da quantidade de partículas submicroscópica envolvidas e seus processos interativos com outras partículas no meio, são desconhecidos da população em geral. Com isso diminui a capacidade de participação e discernimento para fazer as melhores escolhas, de decidir por consumir determinado produto ou não. É necessário que o conhecimento próprio de uma comunidade de conhecimento, como a comunidade dos químicos, retorne ao meio social e proporcione a cada cidadão as condições de participar e decidir com responsabilidade, pois isso tem a ver com qualidade de vida. $O$ que seja qualidade de vida é uma construção social, portanto intersubjetiva, decidida com base em argumentos embasados no conhecimento socialmente repartido.

O conhecimento químico, associado a outros campos científicos, deu ao homem o poder de agir não apenas sobre a forma da matéria inanimada, mas sobre a matéria viva e sobre o fenômeno vida e sua evolução, através da biologia molecular e a engenharia genética, por exemplo.
Esse poder não pode permanecer sob o domínio de poucas pessoas, como alguns biólogos, químicos, engenheiros geneticistas, geneticistas e economistas. Por essas ciências controla-se a natureza em seu curso natural de evolução e criam-se novos organismos e restringe-se a variedade deles. Tal poder construído com base no conhecimento científico precisa ser controlado democraticamente, vigiado e decidido com base em princípios éticos coletivamente assumidos em instâncias que envolvam todos os interesses da sociedade e não apenas especialistas que detêm o poder cultural específico, pois o conhecimento e a cultura são patrimônio de toda a humanidade. As pessoas ativas nessas instâncias de definição dos princípios éticos precisam saber agir e tomar decisões com base nos mesmos conhecimentos científicos, com o mesmo poder de argumentação dos especialistas (comunidades científicas, associações científicas) para que as soluções não sejam propostas com base na racionalidade técnica, mas com base na melhor qualidade de vida das pessoas e do planeta.

Em Ano Internacional da Química, além do reconhecimento justo e merecido da importância da Química no mundo contemporâneo, mostrando suas realizações e as grandes conquistas na melhora da qualidade de vida das pessoas e preservação dos recursos da natureza, não se pode deixar de refletir sobre a responsabilidade que têm os químicos na significação social dos conhecimentos que permitiram essas realizações. Há, por um lado, a evidente importância do fato químico no meio tecnossociocultural e, por outro lado, desconhecimento mais elementar das bases científicas sobre o comportamento da matéria em nível atômico-molecular ou da ciência Química pelas populações. Desconhecendo o que significa determinado produto ou substância no contexto de vida das pessoas, estas não se alertam para possíveis problemas, permanecem alheias aos possíveis efeitos desses materiais no meio em que são utilizados e acabam sendo joguetes da propaganda ou contrapropaganda, 
como no caso dos alimentos e bebidas com aditivos químicos ou sem eles, uso de medicamentos naturais ou artificiais, combate químico ou natural de pragas agrícolas, consumo de produtos orgânicos ou não outros, entre outras situações. O desconhecimento dos princípios mais elementares da ciência Química é notório não apenas em populações pouco escolarizadas, estando presente mesmo no meio acadêmico e entre profissionais de nível superior, mas sem proximidade com o saber químico. Isso mostra que na escolarização básica, mesmo que seja de ensino obrigatório, houve pouca ou quase nenhuma aprendizagem significativa, isto é, que permitisse fazer relações da química escolar com situações do cotidiano e do mundo da vida das pessoas. Nesses aspectos, nenhuma pessoa que teve a oportunidade aprender Química pode “lavar suas mãos”! Assim como as pessoas mais experientes em um grupo familiar ou social é responsável pela significação dos saberes de sobrevivência do grupo, apontando potencialidade e situações de perigo que devem ser evitadas, toda a pessoa que teve acesso ao conhecimento químico e exerce algum papel social ligado a ele tem o compromisso e o dever de exercer seu papel educativo, por exemplo, orientando corretamente o uso de algum defensivo agrícola no processo de comercialização. $O$ mesmo vale para qualquer situação em que há uma intermediação com produto químico e fornecedor e consumidor. Isso vale ainda mais para o processo de fabricação dos produtos, bem como, na elaboração do roteiro de indicações de uso e instruções de seu uso correto.Trata-se, portanto, de responsabilização do papel educativo de todas as instituições e não apenas da escola. Desse ponto de vista, todo químico é também um educador em seu contexto de ação, devendo sentir-se responsabilizado por problemas que venham a afetar a qualidade ambiental e de vida pelo mau uso de algum artefato derivado do conhecimento químico. Deve ser assim em todas as áreas do conhecimento, constituindo o princípio básico da solidariedade humana em defesa de um Planeta melhor, conforme defende Edgar Morin.

Sem dúvida, a educação escolar é a instituição que tem a função social de acesso ao conhecimento sistematizado, como é a Química como matéria de ensino. $O$ que seria uma iniciação consistente nesse conhecimento? A comunidade de educadores químicos, isto é, pessoas que utilizam o conhecimento químico para fazer educação de forma intencional e sistemática em instituição de ensino, busca a melhor resposta com insistência nos últimos 30-35 anos. Não há uma resposta única. Sabemos, apenas, que a aprendizagem em Química, na educação escolar básica, aquela que antecede os cursos superiores, é muito baixa e tem pouco valor para estudantes que não seguem carreiras químicas. Em geral, alguns aprendem "coisas de química", mas não constituem o pensamento químico sobre o real dado e diante de situações concretas que requerem uma atitude que seja correta sob o ponto de vista desse conhecimento. Não cabe analisar aqui as causas, apenas expressar um novo enfoque possível para a significação dos principais conceitos da Química que proporcionam o pensamento químico.

O "pensamento químico" torna-se possível mediante a significação de um sistema coerente de conceitos, isto é, conceitos em que ficam explícitas as relações que devem existir entre os mesmos, dando coerência e autonomia ao pensamento. Nos programas tradicionais de ensino de Química, nos quais se apresentam os conteúdos segundo a lógica de quem conhece a Química, não se constitui a competência do pensamento químico sobre o mundo material, sua transformação e sua permanência. É necessário que a atenção e o olhar sejam dirigidos de forma pedagógica para o objeto sobre o qual o pensamento deve se constituir e então sejam introduzidos conceitos que permitem o diálogo pedagógico sobre o mesmo. Em nosso grupo de pesquisa, GIPEC/Unijuí', propomos a Situação de Estudo (SE) como proposta curricular. Professor(es) e 
estudantes estudam uma Situação da vivência dos alunos sobre diversos pontos de vista, utilizando, para isso, todos os recursos disponíveis, como os livros didáticos, processos da informática, experimentação, pesquisa de campo, conversas com determinados profissionais e outros. Nesse estudo os diferentes componentes disciplinares, por exemplo, da área das Ciências da Natureza e suas Tecnologias, significam conceitos que permitem pensar sobre a Situação em novo nível, sempre de maior generalidade para que, de acordo com princípio vigotskiano, possa formar-se consciência sobre a Situação em estudo ou tomar consciência dela sob outros pontos de vista. As SE são objeto de estudo e pesquisa na formação dos novos professores $\mathrm{e}$ na formação continuada de professores que já atuam no sistema e mostram-se instrumentos interessantes para mudar o ensino de Ciências para melhor nas escolas em que são produzidas. No caso específico da Química, algumas SE são muito interessantes e eficazes para constituir o pensamento químico inicial sobre o mundo, como, por exemplo, a Situação de Estudo do "Ar Atmosférico", dos "Metais", das "Combustões" e outras que já foram testadas e acompanhadas pela pesquisa que temos realizado.

A produção de uma Situação de Estudo, conforme se concebe e se pratica no âmbito do GIPEC/ Unijuí, envolve sempre três grupos de sujeitos: estudantes em formação na Graduação e PósGraduação, professores de escola, docentes universitários envolvidos na formação de novos professores e na formação continuada de professores. Dessa forma os professores tornam-se autores de currículo de ensino e não meros aplicadores de roteiros produzidos por outros e dos quais desconhecem princípios e objetivos, e melhora-se o ensino em duas pontas problemáticas: reorganização curricular e qualificação os professores. 